\title{
O modelo gerencial da educação: contribuições da experiência da Inglaterra ao debate brasileiro
}

Mauricio Almeida Prado

\section{Introdução}

A Inglaterra é uma das principais referências no debate sobre gestão da educação. Seu sistema de educação básica está organizado em ensino primário, secundário, ambos compulsórios, e complementar. O ensino primário, constituído por sete séries, é destinado a crianças de 5 a 11 anos. O ensino secundário, composto de cinco séries, é destinado aos adolescentes de 12 a 16 anos. Já o ensino complementar, voltado para jovens de 17 e 18 anos, apresenta uma organização bastante diversificada, podendo se focar tanto na formação para o trabalho quanto na preparação para universidades.

Embora essa organização da educação básica permaneça vigente desde a década de 1940, a publicação do Education Reform Act (ERA), em 1988, trouxe uma série de mudanças com relação à gestão do sistema educacional. Antes da publicação do ERA, as Local Educational Authorities (LEA), autoridades constituídas pelos governos locais, eram dotadas de grande autonomia administrativa 
na destinação de recursos orçamentários e na fiscalização e acompanhamento das unidades escolares. As escolas e os professores da rede pública, por sua vez, detinham ampla autonomia pedagógica na definição dos conteúdos curriculares a serem ensinados. Já a distribuição dos alunos entre as escolas públicas tinha como critério o local de residência dos alunos. A reforma que se seguiu à publicação do ERA transformou radicalmente o modelo de gestão da educação pública.

Tendo a reforma gerencial da educação na Inglaterra como foco, o presente artigo estrutura-se em cinco partes. A primeira é uma análise dos fundamentos teóricos que estão por trás da Nova Gestão Pública (NGP), um mix eclético de ideias e práticas vindas da administração empresarial e da economia das organizações trazidas para a gestão pública por meio de consultores, acadêmicos, agências internacionais, servidores públicos seniores e políticos (HoOD e Peters, 2004), que nortearam a reforma educacional inglesa. Depois é apresentada uma síntese dos componentes derivados da NGP que caracterizam as reformas gerenciais da educação. Uma vez caracterizado o modelo gerencial da educação, parte-se para a descrição dos componentes presentes no caso da reforma inglesa. Após a descrição da reforma, é feita uma análise da experiência inglesa à luz de seus resultados. A conclusão do artigo busca trazer possíveis insights sobre a temática da administração da educação no Brasil.

\section{Os fundamentos teóricos das reformas gerenciais da educação}

A reforma da educação na Inglaterra se baseou em um conjunto de ideias e se materializou por meio da montagem de uma nova arquitetura institucional construída ao longo dos governos Thatcher (1979-1990), Major (1990-1997) (BARTLETT, et al., 1998) e Blair (1997-2007) (GORARD et al., 2002). $\mathrm{O}$ contexto que permitiu a estruturação da nova arquitetura institucional, a partir de teorias econômicas e administrativas, era de forte descrença pública em relação à qualidade do sistema público de educação básica.

O primeiro conjunto de ideias, que emergiu em meio à discussão sobre a reforma da educação na Inglaterra, tinha por objetivo construir uma institucionalidade que reorganizasse as relações entre os múltiplos agentes da educação, reduzindo a ineficiência do ensino público e os problemas de iniquidade social ocasionados por uma política educacional distante dos anseios da população. Esse primeiro conjunto de ideias está diretamente relacionado à construção, teórica e prática, de uma rede de incentivos visando tornar a burocracia escolar mais responsiva aos usuários de serviços públicos.

A emergência da nova economia institucional nas análises do funcionamento das organizações se deu com a crescente popularidade da Teoria dos Custos de Transação (TCT) e da Teoria da Agência (TA). A TCT compreende mercado e hierarquia como mecanismos alternativos de governança, que devem ser escolhidos a partir da análise das variáveis incerteza e oportunismo (Barney e Hesterly, 2004). A variável incerteza se refere à assimetria de informação entre duas partes. Já o oportunismo representa a possibilidade de os atores adotarem comportamento que busca enganar e confundir a outra parte numa dada transação. Nesse sentido, a escolha do mecanismo de governança depende da análise dos custos associados a cada opção. A TA, por sua vez, representa uma parte da teoria econômica “(...) que 
busca compreender as causas e consequências, para as organizações, da discordância sobre metas" (BARNEY e Hesterly, p. 145, 2004) entre diferentes atores. A TA tem como foco a análise do processo de gerenciamento das organizações a partir das problemáticas da delegação de autoridade, dos mecanismos de monitoramento e de atribuição de incentivos com vistas a alinhar a atuação do agente às expectativas do principal.

Os pressupostos das TCT e TA formam o arcabouço do mecanismo de competição administrada e dos novos sistemas de remuneração atrelados ao desempenho educacional. A competição administrada surge como alternativa que busca conciliar pontos fortes dos modelos de governança examinados pela TCT, na medida em que reconhece, conforme o modelo hierárquico, a importância do governo como agente coordenador de políticas públicas, mas insere características do modelo de mercado a fim de corrigir disfunções do modelo burocrático estatal como a má qualidade dos serviços prestados (Le Grand, 2003). Os novos sistemas de remuneração, por sua vez, surgem do desejo de alinhar o desempenho profissional ao organizacional, desafio teórico próprio da TA (Burguess e Metcalfe, 1999).

O segundo conjunto de ideias diz respeito ao impacto descentralizador da reforma, por meio da autonomia concedida às unidades escolares, que abria espaço para a implementação de arranjos característicos da NGP, tais como redução das linhas de comando (downsizing), empoderamento (empowerment) da gerência escolar e ênfase no alcance de resultados com base na estruturação de sistema de metas de aprendizagem por unidade escolar. Este conjunto de ideias está diretamente ligado a uma nova cultura gerencial, que emergiu a partir da literatura de administração de empresas. As principais origens de seus pressupostos são bibliografias variadas que descrevem práticas de sucesso em diversas organizações.

As teorias administrativas, durante toda sua história, exerceram forte influência sobre os setores público e privado. Durante a maior parte da primeira metade do século XX, os trabalhos sobre

"Depois de mais de três décadas de relativo abandono $e$ separação bastante radical entre administração empresarial e pública, as influências da teoria da administração voltaram a ser observadas no setor público ...”

teorias administrativas exerciam forte influência sobre os setores público e privado. Nesse período, a similaridade entre a administração pública e empresarial marcou a era da Progressive Public Administration (PPA). As fundações, que tornavam os princípios da teoria $\mathrm{da}$ administração intercambiáveis com a administração pública, estavam na 
possibilidade de estudá-la em termos de processos, funções, arquitetura organizacional, eficiência e eficácia. Autores como Frank Godnow, Leonard White, Woodrow Wilson, Luther Gulick, W.F. Willoughby e Frederick Taylor trouxeram contribuições à administração de forma geral.

$\mathrm{O}$ afastamento entre teoria da administração e administração pública se deu mediante a crítica que autores como Wallace Sayre e Dwight Waldo passaram a fazer sobre a linha da PPA. A crítica desses autores sustentava a posição de que a PPA baseava-se na estrita separação entre política e administração pública (LYNN, 2001). O acolhimento dessa crítica pelos novos autores identificados com o tema minou os fundamentos teóricos compartilhados pelos estudiosos da administração dos setores privado e público. Apesar dos esforços para se restabelecer a legitimidade do campo da administração pública, seus fundamentos ficaram enfraquecidos pela falsa premissa de que os estudos sobre administração pública, após Dwight Waldo, não poderiam se aproximar do ponto de vista dos fundadores da PPA (Svara, 2001). O resultado disso foi o afastamento da administração pública das teorias administrativas e seu posterior encastelamento no âmbito da ciência política, das ciências sociais e do direito administrativo.

O retorno das discussões sobre a administração pública, sob a ótica da teoria da administração, é bastante recente. Depois de mais de três décadas de relativo abandono e separação bastante radical entre administração empresarial e pública, as influências da teoria da administração voltaram a ser observadas no setor público a partir de meados da década de 1980, sob o nome de gerencialismo (managerialism). A emergência do managerialism se deveu à crise de credibilidade que a administração pública atravessava em vários países, abrindo espaço para uma demanda crescente por práticas da administração empresarial. Mas a reaproximação entre a administração pública e privada, observada na década de 1980, não foi similar em todos os países (SAINT-Martin, 1998). Os países que estabeleceram uma linha divisória mais forte entre ambos continuam muito reticentes em aceitar as práticas gerenciais do setor privado. Já países que tinham uma tradição maior da participação do setor privado na administração pública revelaram maior grau de abertura para teorias e métodos administrativos trazidos por consultorias empresariais. Esse é o caso da Inglaterra.

\section{As reformas gerenciais da educação}

A gestão da educação básica em vários governos tem passado, desde o fim da década de 1980, por uma série de reformas cujo foco é a melhoria da qualidade (Morton, 2006; Datnow e Park, 2009). Essas reformas educacionais, denominadas como gerenciais por vários autores, contemplam a adoção de uma série de inovações, cujo eixo principal é a introdução de políticas de padronização curricular, avaliação educacional e a estruturação de sistemas de metas na educação básica (Fuhrman, 2001; Soguel e Jacard, 2008). Outras inovações recorrentemente observadas nesses modelos de reformas são as novas formas de remuneração na carreira docente, de gestão escolar e da rede de ensino, e a introdução da competição administrada.

As políticas de padronização curricular se referem tanto à escolha, por parte do governo, dos conteúdos para cada série do ensino, quanto à definição dos materiais 
didáticos que se espelham nesse currículo (LEVIN, 2008). A avaliação educacional compreende a aplicação de testes padronizados com o objetivo de avaliar os níveis de proficiência dos alunos. A adoção de um sistema de avaliação da aprendizagem dos estudantes é indispensável neste modelo de reforma, na medida em que ela representa o principal instrumento de medição do progresso da escola em termos de qualidade do ensino. A estruturação do sistema de metas na educação, por sua vez, se refere ao desenho de um sistema que permite a responsabilização, perante a comunidade atendida por cada escola pública, e a sociedade de forma geral, de todos os envolvidos na prestação de serviços educacionais públicos. Esse sistema se concretiza por meio da definição de metas de aprendizagem por unidade escolar e para a rede de ensino ao longo do tempo. de um sistema de accountability minimamente eficaz. Alinhado aos pontos centrais, o movimento reformista também é marcado por uma série de mudanças complementares - variando caso a caso que visam reforçar a atuação dos vários atores da educação, conforme a estratégia associada ao núcleo principal da reforma. Embora a quase totalidade das reformas educacionais contemple a adoção de apenas alguns componentes (MAroy, 2009), o Quadro 1 reúne todas as inovações gerenciais que podem ser observadas na literatura especializada.

\section{A reforma gerencial da educação na Inglaterra}

As diversas experiências de reformas gerenciais na educação mostram que tais

\section{Quadro 1: Componentes das reformas gerenciais na educação}

\begin{tabular}{|l|l|}
\hline $\begin{array}{l}\text { Componentes gerenciais que compõem } \\
\text { o núcleo da reforma }\end{array}$ & $\begin{array}{l}\text { Componentes gerenciais de cunho } \\
\text { reforçador }\end{array}$ \\
\hline 1. Padronização dos conteúdos curriculares & $\begin{array}{l}\text { 4. Bonificação por resultados } \\
\text { 5. Adoção de sistemas de progressão por } \\
\text { mérito na carreira docente }\end{array}$ \\
\hline 2. Avaliação educacional & $\begin{array}{l}\text { 6. Descentralização financeira e } \\
\text { administrativa da gestão escolar }\end{array}$ \\
& $\begin{array}{l}\text { 7. Mudanças no papel e na forma de } \\
\text { atuação da gerência escolar }\end{array}$ \\
\hline 3. Estruturação de um sistema de metas & $\begin{array}{l}\text { 8. Estruturação de um sistema de apoio à } \\
\text { performance escolar } \\
\text { 9. Competição administrada entre as } \\
\text { unidades escolares }\end{array}$ \\
\hline
\end{tabular}

Fonte: Elaboração própria.

Hoje, a análise de um número relativamente grande de casos permite identificar esses mecanismos como centrais às experiências de reformas educacionais no mundo. $\mathrm{O}$ núcleo da reforma garante as condições indispensáveis para a montagem reformas são marcadas pela grande variabilidade dos mecanismos adotados (Fuhrman, 2001; Soguel e Jacard, 2008). São raros os países que adotam a maior parte dos componentes identificados com a reforma. A Inglaterra, no entanto, é o 
caso mais bem acabado de introdução de praticamente todos os componentes do modelo gerencial ${ }^{1}$. Segundo Soguel e Jacard (2008), a Inglaterra é um caso único de opção política por um sistema moldado tanto pela competição administrada quanto pela estruturação de um sistema de metas e apoio à performance escolar. Essa característica faz da experiência inglesa um caso que merece atenção especial.

A publicação do ERA, em 1988, representou a maior mudança já realizada na administração do sistema de educação básica da Inglaterra, desde o Education Act de 1944 (ChiтTr, 2004). Por meio do ERA, o governo definiu o currículo nacional obrigatório para todas as escolas públicas do país, um sistema nacional de avaliação da aprendizagem, uma descentralização financeira e administrativa progressiva $\mathrm{da}$ gestão escolar e o início da montagem da competição administrada, ponto mais polêmico da reforma.

\section{$O$ núcleo da reforma gerencial}

A definição rigorosa e focada de um currículo é associada, na literatura internacional, a ganhos de desempenho nas avaliações internacionais (SCHMIDT e PRAWAT, 2006). Esse processo de criação de currículo se refere à função de normatização de competências e conteúdos a serem adquiridos em cada etapa da educação. O currículo é um dos mecanismos utilizados pelo governo para influenciar práticas e direcionar resultados (Westbury, 2008). Essa função envolve a difícil escolha, entre os muitos conteúdos e competências existentes, daqueles que devem constar no sistema de ensino. Tais escolhas elencam as prioridades do governo em termos de política educacional.

A introdução do currículo nacional inglês adveio na esteira da publicação do ERA, que especificava quais disciplinas eram de ensino compulsório nas escolas públicas (Education Reform Act, 1988). A confecção dos parâmetros curriculares, a partir de 1988, foi voltada para construção de um currículo nacional que visava uniformizar as competências e conteúdos a serem dominados pelos estudantes em cada uma das séries do ensino. A publicação da primeira versão do currículo nacional - ao apresentar os conteúdos fundamentais que deveriam guiar a atuação dos professores, a confecção de materiais didáticos e das avaliações externas - trouxe maior clareza em relação ao que deveria ser ensinado. Esse processo, no entanto, foi cercado de dificuldades e demandou ajustes sucessivos, a fim de contornar problemas como sobrecarga e falta de clareza curricular - os dois principais problemas da política curricular (POPHAM, 2010) -, além das dificuldades de ajustamento mútuo entre os limites do sistema de avaliação e as pretensões do currículo nacional (WHETTON, 2009).

A definição de um amplo sistema de avaliação educacional, em conjunto com o estabelecimento do currículo nacional, é o aspecto mais centralizador da reforma recente da educação na Inglaterra (WHITTY, 2008). O sistema de avaliação educacional ou externa é o termo empregado para descrever uma gama de ações empreendidas com objetivo de produzir informações a respeito do conhecimento e habilidades dos estudantes. As informações dessas avaliações são disponibilizadas na forma de indicadores de desempenho.

A avaliação externa tem, primordialmente, duas funções (BERry e AdAMson, 2010). A primeira é viabilizar julgamentos sobre o desempenho de indivíduos, equipes, escolas e do sistema educacional (caráter somativo da avaliação). A segunda é gerar informações que possam ser utilizadas para 
promover melhorias quanto à aprendizagem (caráter formativo da avaliação). As avaliações externas realizadas na Inglaterra, até 1988, eram o Certificate of Secondary Education (CSE) e o General Certificate of Education (GCE), testes aplicados aos alunos concluintes do $12^{\circ}$ ano, último ano do ensino compulsório. A publicação do ERA culminou na definição de três novas avaliações: o Key Stage 1 ( $3^{\circ}$ ano), Key Stage 2 ( $7^{\circ}$ ano), Key Stage 3 ( $10^{\circ}$ ano) e na remodelação do CSE, que tornou-se o General Certificate of Secondary Education (GCSE) ou, simplesmente, Key Stage 4. Cada uma dessas avaliações toma por base um conjunto de conhecimentos e habilidades esperados dos estudantes em cada ciclo de ensino. A partir dos resultados das avaliações passaram a ser publicadas tabelas de desempenho (performance league tables) de todas as escolas públicas. Esse sistema representou, inicialmente, o fortalecimento da função somativa de avaliação externa (JAMES, 2010).

A estruturação de um sistema de metas na educação está diretamente ligada ao desenvolvimento da avaliação educacional. O desdobramento das metas globais de aprendizagem, estabelecidas a partir das Citizen's Charter, em direção a metas regionais e, por último, metas por unidade escolar, tem por objetivo promover o alinhamento de esforços entre agentes da educação. A definição de metas funciona como mecanismo de incentivo ao desempenho e coordenação entre diferentes níveis. Esse desdobramento de metas até o nível da unidade escolar marcou a introdução da administração por objetivos na gestão da educação (WHiTTY, 2008).

\footnotetext{
Os componentes de cunho reforçador da reforma

O ponto mais polêmico da reforma da educação na Inglaterra foi a introdução da
}

competição administrada (quasi-markets) na educação. A adoção desse mecanismo tinha como objetivo melhorar o nível dos serviços educacionais por meio do estabelecimento de uma abordagem competitiva inexistente no modelo anterior (Johnson, 2004). O mecanismo de competição administrada busca conceder aos pais o direito de escolher a escola de seus filhos. Até a publicação do ERA, a escola, que cada criança ou adolescente deveria

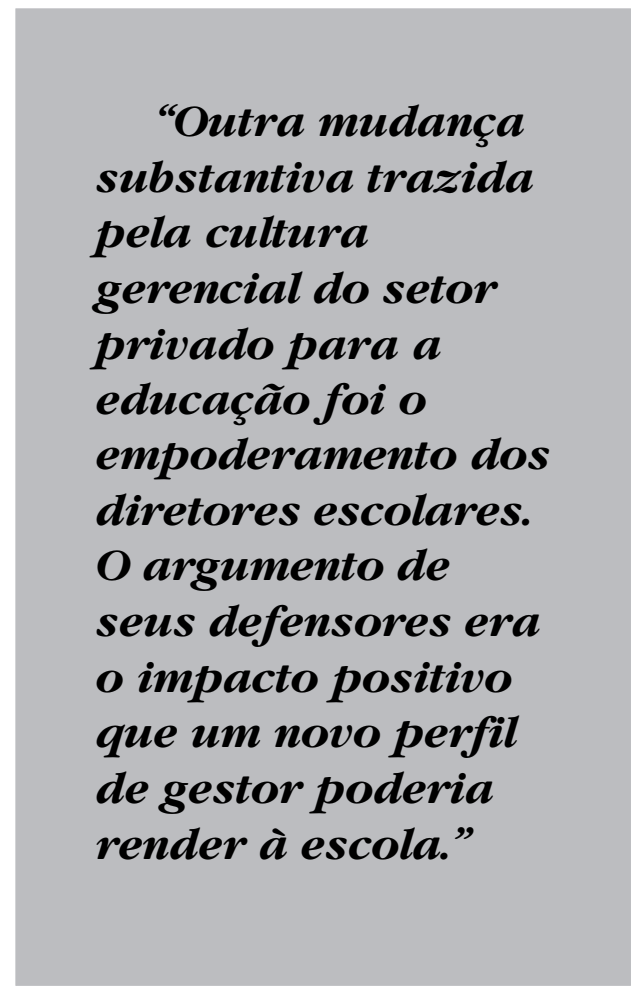

frequentar, era definida pelo estado com base na proximidade da residência do aluno. A adoção da competição administrada rompeu essa limitação, ampliando as escolhas disponíveis de modo a criar um ambiente mais competitivo entre as várias escolas.

A competição administrada, para ser efetiva, dependia da disponibilidade de 
informações sobre a qualidade da educação nas diversas escolas existentes. Com objetivo de fornecer aos pais e alunos informações claras sobre o nível das escolas, foi necessário adotar um sistema de sinais e incentivos que permitam a realização efetiva do processo de escolha. Os mecanismos adotados, encarregados de fornecer tais sinais, foram o maior número de testes aplicados ao longo do ensino (base para publicação das performance league tables) e as inspeções de qualidade foram realizadas nessas escolas pelo Office of Standards Education (Ofsted), visando maior transparência quanto ao desempenho das escolas (Johnson, 2004).

A introdução da competição administrada também dependia da alteração do mecanismo de captação de recursos (formula funding). Se no modelo anterior as escolas recebiam recursos fixos do governo, no novo sistema uma parte significativa do montante destinado às escolas passou a ser proporcional à quantidade de alunos matriculados. Tais mudanças formavam um mecanismo, cuja lógica de funcionamento era permitir a expansão das melhores escolas, que passariam a receber maior número de matrículas e, consequentemente, maior volume de recursos, e forçar escolas de pior desempenho a melhorarem seu nível de qualidade, sob o risco de o número de alunos matriculados, e consequentemente de recursos, ser reduzido.

Outra transformação, pela qual o sistema educacional inglês passou, foi a concessão de maior autonomia gerencial às escolas, por meio do ERA, o que ficou conhecido como Local Management School (LMS). A nova cultura gerencial emergente considerava que a descentralização das decisões às unidades escolares, em detrimento das LEA, representava uma aproximação desejada entre escola e seus usuários. O raciocínio era que o nível escolar tinha mais consciência de seus problemas do que uma burocracia regional (LEVACIC, 1995).

Outra mudança substantiva trazida pela cultura gerencial do setor privado para a educação foi o empoderamento dos diretores escolares. $\mathrm{O}$ argumento de seus defensores era o impacto positivo que um novo perfil de gestor poderia render à escola. A valorização de um novo perfil de gerência escolar está diretamente relacionada com a transferência de autonomia e responsabilidade às escolas (LMS) (Hopkins, 2003). A nova cultura gerencial emergente vislumbrava uma grande transformação das competências do diretor escolar, estimulando o desenvolvimento de habilidades empreendedoras, de liderança e maior responsividade frente às demandas de qualidade na educação (JAMEs e VINCE, 2001).

Além do provimento das performance league tables, as ações do governo, voltadas a melhorar a qualidade da educação, incluíram a criação de um sistema de intervenção direta nas unidades escolares. $\mathrm{O}$ governo, em vez de se comportar como um ator passivo, que apenas disponibilizava informações, passou a coordenar ações diretas nas unidades escolares, com o objetivo de melhorar o seu desempenho nas avaliações. Entre os órgãos de apoio à performance escolar na década de 1990, o Ofsted é o que mais se destaca. Trata-se de uma agência executiva que tem por objetivo auxiliar as unidades escolares a melhorarem sua performance por meio de políticas localizadas de auditoria e intervenção. O Ofsted avalia desde a gestão financeira e administrativa, até questões pedagógicas (LEVACIC, 1995). As suas principais funções são acompanhar escolas de baixo desempenho, construindo estratégias de ação localizada, 
oferecer feedback à gerência escolar e informações qualitativas para as decisões dos pais (Johnson, 2004).

A nova cultura gerencial também foi manifestada pela introdução da política de promoção por mérito na educação (Performance Related Pay - PRP). A emergência do PRP no setor educacional foi fruto da percepção de que era possível criar um mecanismo eficaz de motivação para professores (Cutler e WAine, 1999). A política de remuneração vigente até 1999 era baseada em aumentos periódicos para os professores em seus primeiros anos e, depois, numa escala de nove faixas salariais distintas e crescentes (ADNETT, 2003). Os fatores que determinavam a classificação do professor ao longo dessas faixas salariais eram a experiência, a formação acadêmica e a ocupação de cargos de chefia.

A nova política de promoção para a classe docente manteve a escala incremental nos primeiros anos dos novos professores, até o nível nove da antiga escala salarial. A partir do nível nove os professores passaram a ser avaliados, por meio de medidas objetivas e subjetivas de desempenho, pelo diretor escolar (Burgess e PROPPER, 2007). Embora fosse o diretor escolar quem decidia se um docente deveria ser aprovado para nova escala salarial, denominada de Upper Pay Scale (UPS) (AtKInson et al. 2004), essas decisões deveriam ser aprovadas pelo governing body de cada escola e, somente após a auditoria de um consultor externo, elas eram efetivadas. Os professores aprovados na avaliação, ao alcançar o patamar mínimo exigido, tinham acréscimo de cerca de 10\% em seu salário anual (ATKINSON et al., 2004). A escala da UPS era dividida em cinco faixas. A ascensão nas faixas tinha por base a avaliação de cinco aspectos (CUTLER e Waine, 2005): progresso do aluno; efetividade profissional; gerenciamento e avaliação do ensino; conhecimento no seu campo de ensino; e características profissionais.

\section{Análise da reforma gerencial da educação na Inglaterra}

A avaliação da reforma da educação na Inglaterra não é simples, uma vez que não é possível isolar o efeito de cada um dos componentes introduzidos para aferir seus resultados. No entanto, a análise dos resultados alcançados nas avaliações externas é parâmetro adequado para avaliar a efetividade do conjunto das mudanças introduzidas. As avaliações têm mantido o mesmo nível de dificuldade ano após ano, sendo pouco plausível a ideia de que os dados não são confiáveis para a análise da reforma (GLENNERSTER, 2002).

O KS4, teste realizado ao final do ensino secundário obrigatório, criado em 1963, indica uma melhoria significativa. A Tabela 1 identifica o percentual de alunos que alcançaram o nível de desempenho exigido.

A evolução positiva dos resultados poderia ter sido provocada pelo aumento dos gastos do governo com a educação. Mas a evolução dos gastos públicos na Inglaterra não é justificativa adequada para tal suposição, uma vez que o grande crescimento dos gastos com educação, entre as décadas de 1960 e 1970, não foi acompanhado por melhoria no desempenho do KS4 (GlenNerster, 2007). Essa constatação é coerente com pesquisas que avaliam que o aumento de recursos aplicados na educação não leva necessariamente a ganhos de qualidade (HanusheK, 2003). O baixo reflexo do aumento dos investimentos nos resultados do KS4, até 1980, indica que, embora tenha ocorrido pequeno aumento no gasto com educação, entre 1988 e 2001, as modificações introduzidas pela reforma 
Tabela 1: Percentual de alunos que atingiram a meta no KS4

\begin{tabular}{c|c|c|c|c|c}
\hline Ano & \% & Ano & \% & Ano & \% \\
\hline 1963 & 16 & 1979 & 24 & 1995 & 44 \\
\hline 1964 & 18 & 1980 & 24 & 1996 & 45 \\
\hline 1965 & 20 & 1981 & 25 & 1997 & 45 \\
\hline 1966 & 20 & 1982 & 26 & 1998 & 46 \\
\hline 1967 & 21 & 1983 & 26 & 1999 & 48 \\
\hline 1968 & 22 & 1984 & 27 & 2000 & 49 \\
\hline 1969 & 22 & 1985 & 27 & 2001 & 50 \\
\hline 1970 & 23 & 1986 & 27 & 2002 & 52 \\
\hline 1971 & 23 & 1987 & 26 & 2003 & 53 \\
\hline 1972 & 24 & 1988 & 30 & 2004 & 54 \\
\hline 1973 & 23 & 1989 & 33 & 2005 & 56 \\
\hline 1974 & 23 & 1990 & 35 & 2006 & 59 \\
\hline 1975 & 23 & 1991 & 37 & 2007 & 62 \\
\hline 1976 & 23 & 1992 & 38 & 2008 & 65 \\
\hline 1977 & 23 & 1993 & 41 & 2009 & 70 \\
\hline 1978 & 24 & 1994 & 43 & 2010 & 75 \\
\hline
\end{tabular}

Fonte: Brooks e Tough (2006) - até 2005; Departament of Education - até 2010.

tiveram impacto na melhoria dos níveis de aprendizagem (JoHNSON, 2004).

A evolução do desempenho educacional na Inglaterra, após a construção de um forte sistema de accountability, se relaciona com as evidências de uma série de pesquisas sobre os efeitos de reformas similares sobre o nível de proficiência dos alunos. Ao analisarem reformas educacionais semelhantes nos EUA, Carnoy e Loeb (2002) encontraram evidências consistentes de que sistemas de accountability fortes, caracterizados pela imposição de consequências a escolas e professores, tinham efeitos positivos sobre o desempenho dos alunos nas avaliações externas. Hanushek e Raymond (2006), do mesmo modo, encontraram evidências de que sistemas de accountability, que impunham consequências aos resultados por meio de prêmios ou sanções, proporcionavam melhorias significativas em termos de aprendizagem. Os autores também encontraram evidências de que sistemas educacionais, que apenas publicavam os resultados das avaliações, não apresentavam melhoras em relação àqueles que não tinham qualquer programa de accountability.

O debate em relação aos vários componentes da reforma não é, todavia, tão conclusivo quanto a melhoria dos indicadores de aprendizagem aparenta. Entre as críticas observadas estão: a) a possível associação entre melhoria de desempenho nas avaliações e redução do currículo; b) a possível associação entre melhoria de desempenho nas avaliações e incremento da prática do teaching to the test, c) os problemas decorrentes do sistema de avaliação; d) os possíveis efeitos negativos da publicação das performance league tables; e) o possível impacto segregacionista decorrente da introdução da competição administrada (Burgess, 2004); e f) os possíveis efeitos negativos da introdução de um sistema seletivo de progressão na carreira.

As políticas de materialização de currículos oficiais sempre repercutem na mídia e ganham notoriedade pública. $\mathrm{O}$ caso da Inglaterra não fugiu à regra. $\mathrm{O}$ anúncio do currículo nacional, em 1988, 
foi cercado de controvérsias, até mesmo dentro do governo conservador. A fim de reduzir a oposição política, docente e acadêmica, o então secretário da Educação e Ciência, Kenneth Baker, optou por um currículo amplo, que incluía os interesses e visões de variados grupos. Esse problema foi potencializado tão logo o governo iniciou a montagem das avaliações externas. Os governos conservadores e trabalhistas, a fim de contornar os problemas associados à sobrecarga curricular, introduziram mudanças com objetivo de reduzir os conteúdos inicialmente previstos nos parâmetros curriculares (OATES, 2010). Mas a mudança trazia à tona uma polêmica: a transformação da ideia inicial de currículo básico em currículo mínimo, denominação pejorativa associada aos potenciais efeitos negativos da redução das expectativas de aprendizagem na educação. Esse enxugamento curricular, criticado por alas dos principais partidos ingleses e por vários acadêmicos, levantava a hipótese de que a melhoria no desempenho escolar poderia estar associada, ao menos em parte, à redução curricular (STOBART, 2009).

Outra possível associação, citada pelos críticos das reformas gerenciais na educação, é o aumento da intensidade do ensino voltado a preparar os estudantes para avaliações externas e para melhoria nos indicadores de aprendizagem. O fundamento dessa crítica está no fato de que os testes padronizados de larga escala encontram limites quanto à avaliação de determinadas competências (NEWTON, 2009). Os exemplos mais citados de lacunas nessas avaliações se referem às competências de escrita, dadas as dificuldades de correção em larga escala de questões dissertativas, e às competências auditivas e comunicativas, incapazes de serem aferidas por meio de questões escritas.
Essas limitações acabam gerando incentivos perversos para uma ênfase maior nos conteúdos e competências que podem ser aferidos por meio de avaliações de larga escala. Esse efeito, popularmente conhecido como teaching to the test, é bastante polêmico, na medida em que levanta a questão de que a melhoria de desempenho, observada nas avaliações externas, não necessariamente significaria ganhos reais de aprendizagem.

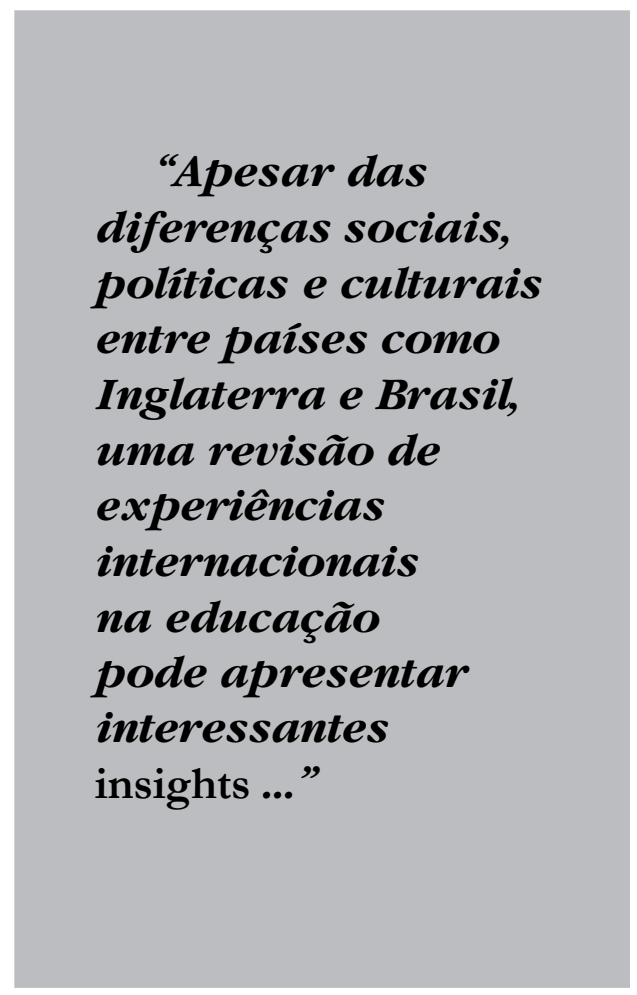

Os sistemas de avaliação externa também não são imunes a falhas e distorções. Kane e Staiger (2002), numa análise dos sistemas de accountability nos EUA, afirmam que as escolas, em razão da pressão crescente por resultados, têm incorrido em ações de manipulação da relação de alunos que fazem as provas, barrando alunos de pior desempenho (gaming incentives) a fim de inflar seus 
resultados. Tais escândalos, ao receberem grande repercussão da mídia, acabam reduzindo a confiabilidade dos resultados e, consequentemente, a legitimidade da política.

O debate acerca dos possíveis efeitos negativos da publicação de indicadores de desempenho e das performance league tables é um dos pontos polêmicos da reforma gerencial. A polêmica em relação ao tema culminou, inclusive, na diferenciação da política de publicação de indicadores entre Inglaterra e País de Gales. Enquanto a Inglaterra mantém, até hoje, a publicidade acerca dos indicadores, o País de Gales a extinguiu em 2001. Os principais motivos para extinção da publicação dos indicadores foram a oposição da classe docente ao possível caráter segregacionista da publicidade (Burgess et al., 2010). Utilizando-se das comparações possibilitadas por esse experimento natural, Burgess et al. "(...) acham provas sistemáticas, significativas e robustas de que abolir tabelas de classificação escolares reduziram notadamente a efetividade escolar no País de Gales" (Burgess et al., 2010, p. 2, tradução nossa). ${ }^{2}$ Os mesmos autores avaliaram que a redução da efetividade escolar no País de Gales foi maior nas escolas de desempenho inferior. A esperada redução da segregação também não foi verificada. Ou seja, a pesquisa não encontrou evidência “(...) que a mudança de política pública teve impacto significativo tanto na classificação por habilidade quanto naquela por status socioeconômico" (Burgess et al. 2010, p. 22, tradução nossa). ${ }^{3}$

O ponto mais polêmico da reforma foi a introdução da competição administrada. Vários estudos foram realizados para avaliar os efeitos desse componente na qualidade da educação. Bradley e Taylor (2002), por exemplo, realizaram uma pesquisa buscando estimar os impactos da competição administrada no desempenho escolar e na segregação do ciclo educacional secundário na Inglaterra. Analisando os efeitos da competição administrada sobre o desempenho escolar, Bradley e Taylor destacaram que a concorrência entre unidades escolares produz pressões que melhoram o desempenho das escolas nos exames compulsórios. Já os efeitos da competição administrada sobre a equidade receberam duas menções. A primeira é de que as escolas de maior desempenho experimentaram uma redução na proporção de alunos vindos de famílias mais pobres. A segunda é de que existem indícios de que o efeito segregativo seria maior em áreas metropolitanas. Confrontando os efeitos positivos sobre o desempenho escolar e os efeitos negativos em termos de segregação social, Bradley e Taylor alegam que os primeiros são maiores em magnitude do que os segundos, de forma que "(...) ponderando, o quase-mercado tem trazido benefícios" (BRADley e TAYLOR, 2002, p. 312 , tradução nossa). ${ }^{4}$

A introdução de sistemas de progressão por mérito para docentes também recebe muitas críticas das entidades de classe e de parte da academia. Em uma pesquisa realizada pelo sindicato dos professores no Reino Unido em 2000, mais de $88 \%$ dos professores se mostraram contrários ao modelo de PRP adotado na Inglaterra (FARrel e Morris, 2002). Segundo as entidades sindicais docentes, os efeitos negativos do PRP seriam o aumento do stress, da insatisfação, do afastamento, do adiantamento da aposentadoria e do abandono da carreira. Apesar das críticas, estudos empíricos realizados a fim de aferir os efeitos da introdução da progressão por mérito na carreira docente, para melhoria da aprendizagem dos estudantes, 
identificaram efeitos positivos do novo sistema. Atkinson et al. (2004), ao analisarem o grau de efetividade do PRP em relação ao progresso dos alunos, entre as avaliações compulsórias realizadas aos 14 (KS3) e 16 (GCSE) anos, concluíram que: a) o sistema de PRP tem reflexos positivos sobre o esforço dos professores e, consequentemente, sobre o desempenho dos alunos; e b) os professores respondem aos incentivos financeiros diretos.

\section{Contribuições ao debate brasileiro}

As últimas décadas ficaram marcadas pela emergência e consolidação da NGP como veículo de ideias para as reformas gerenciais na educação. Essa corrente trouxe vários instrumentos de gestão que eram adotados no setor privado há algum tempo. Entre os mecanismos presentes nas recentes reformas educacionais estão as políticas de padronização curricular, avaliação educacional, estruturação de sistemas de metas na educação, bonificação por resultados, adoção de sistemas de progressão por mérito na carreira docente, descentralização da gestão escolar, mudanças no papel e na forma de atuação da gerência escolar, estruturação de um sistema de apoio à performance escolar e a competição administrada. A análise da introdução dessas inovações na Inglaterra, apesar das críticas, parece ter rendido bons resultados em termos de aprendizagem escolar.

Apesar das diferenças sociais, políticas e culturais entre países como Inglaterra e Brasil, uma revisão de experiências internacionais na educação pode apresentar interessantes insights que, se devidamente contextualizados, proporcionam análises comparativas enriquecedoras. Exemplo disso é a crescente utilização, pelo governo federal e por alguns estados brasileiros, de avaliações aplicadas ao longo do ensino básico. Os resultados das avaliações, quando disponibilizados por unidade escolar, geram informações sobre a aprendizagem e possibilitam que gestores da área educacional identifiquem as principais deficiências de desempenho de cada escola e rede de ensino. As informações advindas desses sistemas de avaliação, se disponibilizadas de maneira clara e objetiva, podem constituir-se em importantes indicadores para que a comunidade de cada escola pressione os governos e a gerência escolar por ações concretas para melhoria do ensino.

Uma lacuna observada na política educacional do governo federal e de vários governos municipais e estaduais, em relação à experiência inglesa, é a ausência de um currículo oficial que oriente efetivamente as escolas e redes de ensino. Os parâmetros curriculares, publicados na década de 1990 pelo governo federal, e as diretrizes curriculares, publicadas pelo Conselho Nacional de Educação, não apresentam com clareza as competências e conteúdos que devem ser priorizados em cada série do ensino básico. A ausência do currículo acaba por transformar o livro didático na única ferramenta curricular à disposição dos professores. Ou seja, quando o governo renuncia seu papel na definição do currículo, é o material didático que acaba direcionando o currículo, e não o contrário. Mas na medida em que os livros geralmente apresentam conteúdo maior do que o tempo disponível para seu ensino, os professores são forçados a realizarem escolhas arbitrárias, gerando disparidade nos conteúdos lecionados numa mesma série.

Outro insight que a experiência inglesa nos mostra, e que é alvo de intenso debate 
no Brasil, é com relação aos efeitos da ampla publicidade dos resultados por unidade escolar. Enquanto na Inglaterra a disponibilização das informações sobre o rendimento das escolas, por meio das performance league tables, constituiu um dos alicerces da reforma da educação, o País de Gales deixou de publicar os resultados por escola a partir de 2001. A análise dos resultados dessa opção aponta para um crescimento maior da efetividade educacional na Inglaterra do que no País de Gales. Ou seja, diferentemente do que afirmam os críticos, parece que a ampla publicidade do desempenho por unidade escolar tem efeitos positivos sobre a melhoria da qualidade da educação. A possibilidade de adotar tal medida no Brasil, além de promover maior accountability entre sociedade e poder público, reconheceria que as ações do estado têm maiores chances de sucesso quando ocorre a efetiva pressão da sociedade sobre os problemas nela existente. Sua adoção seria simples, na medida em que já existem avaliações disponíveis, cabendo aos governos estaduais e municipais dar maior publicidade e facilitar a compreensão das informações para os pais, alunos e a sociedade.

A introdução de consequências para as escolas, professores e demais funcionários da educação também é assunto polêmico no Brasil. Embora evidências internacionais mencionadas apontem que sistemas de premiação e sanção têm resultados positivos em termos de aprendizagem, o recente abandono da política de bonificação de resultados por parte do governo de Nova York (RAnd Education, 2011) - uma das práticas mais comuns de premiação em sistema de accountability forte - levantou a hipótese de que esse mecanismo não tem efeitos sobre a melhoria da qualidade da educação. A diferença do contexto de Nova York, em relação a experiências recentes de alguns estados brasileiros, deve ser considerada para fins de análise da política. Os estados americanos, desde a publicação da lei No Child Left Behind, passaram a adotar sistema de accountability, repleto de consequências sobre escolas e sistemas de ensino, que não encontra parâmetros equivalentes às experiências estaduais no Brasil. Assim, dadas as diferenças de contexto e o curto período de vigência das políticas de bonificação no Brasil, não é possível chegarmos a conclusões sobre seus efeitos. O pouco tempo de vigência dessa política não impede, no entanto, a realização de análises qualitativas de seus efeitos sobre a implementação de outros componentes da reforma, como a padronização curricular, e sobre o engajamento das escolas em ações pedagógicas que visem corrigir problemas detectados por meio das avaliações externas.

Outro diferencial que se introduziu na Inglaterra, mas não existe no Brasil, é a existência de um órgão encarregado de intervir em escolas com baixo desempenho, com objetivo de auxiliar e cobrar ações que proporcionem melhoria da qualidade do ensino na própria unidade escolar. A criação de um órgão voltado para empreender ações de caráter localizado permite contrabalançar fontes de pressão com fontes voltadas para construção e fortalecimento de capacidade escolar. Assim, diretores escolares e professores podem ter feedback dos problemas de escola e construir formas concretas de ação, a fim de superar lacunas administrativas e pedagógicas. (Artigo recebido em outubro de 2011. Versão final em novembro de 2011). 


\section{Notas}

1 O único componente da reforma não adotado na Inglaterra é o bônus por resultados.

2 (...) find systematic, significant and robust evidence that abolishing school league tables markedly reduced school effectiveness in Wales.

3 (...) that the policy change has had a significant impact on either sorting by ability or by socioeconomic status.

4 (...) on balance the quasi-market has been beneficial.

\section{Referências bibliográficas}

AdnetT, Nick. Reforming Teachers' Pay: Incentive Payments, Collegiate Ethos and UK Policy. Cambridge Journal of Economics, v. 27, p. 145-157, 2003.

Atkinson, Adele; Burguess, Simon; Croxson, Bronwyn; Gregg, Paul; Propper, Carol; Slater, Helen; Wilson, Deborah. Evaluating the Impact of Performance Related Pay for Teachers in England. CMPO Working Paper, n. 04/113, Dec. 2004.

Barney, Jay B; Hesterly, William. Economia das Organizações: Entendendo a Relação entre as Organizações e Análise Econômica. In: CLEGG, Stewart et al. Handbook de Estudos Organizacionais: Ação e Análise Organizacional. São Paulo: Ed. Atlas, 2004. v. 3.

Bartlett, Will; Roberts, Jennifer A.; Le Grand, Julian. A Revolution in Social Policy: Quasi-Markets Reforms in the 1990s. Bristol: The Policy Press, 1998.

Berrey, Rita; Adamson, Bob. Assessment Reform Past, Present and Future. In: Berrey, Rita; Adamson, Bob. Assessment Reform in Education: Policy and Practice. London: Springer, 2010.

Bradley, Steve; TAYLOR, Jim. The Effect of the quasi-market on the efficiency-equity trade-off in the Secondary School Sector. Bulletin of Economic Research, London, v. 54, n. 3, p. 295-314, 2004.

Brooks, Richard; Tough, Sarah. Pupil Attainment: Time for a three Rs guarantee. Institute for Public Policy Research, Dec. 2006.

Burguess, Simon; Metcalfe, Paul. The Use of Incentives Schemes in the Public Sector and Private Sectors: Evidence of British Establishments. CMPO Working Paper Series, $\mathrm{n}$. 00/15, Oct. 1999.

Burguess, Simon; Propper, Carol. Performance Pay in the Public Sector: a Review of the Issues and Evidence. CMPO Office of Manpower Economics, Nov. 2007.

Burguess, Simon; Wilson, Deborah; Worth, Jack. A natural experiment in school accountability: the impact of school performance information on pupil progress and sorting. CMPO Working Paper Series, n. 10/246., Oct. 2010.

Carnoy, Martin; Loeb, Susanna. Does External Accountability Affect Student Outcomes? A Cross-State Analysis. Educational Evaluation and Policy Analysis Winter, v. 24, n. 4, p.305-331, 2002. 
Chiтtr, Clyde. Education Policy in Britain. New York: Palgrave Macmillan, 2004.

Cutler, Tony; Waine, Barbara. Rewarding Better Teachers. Educational Management \& Administration, London, v. 27, n. 1, p. 55-70, 1999.

. Not So Seamless? Performance Related Pay and Financial Control in

English Schools. Public Money \& Management, London, v. 25, p. 67-71, Jan. 2005.

Datnow, Amanda; Park, Vicki. Conceptualizing Policy Implementation: Large-Scale Reform in an Era of Complexity. In: SyKes, Gary; SCHNEIDER, Barbara; Plank, David N. Handbook of Education Policy Research. New York: Routledge Publishers, 2009.

Dfes; Higher Standards, Better Schools for All: More choice for Parents and Pupils. Department for Education and Skills. London: October, 2005.

Education Reform ACT. Her Majesty's Stationery Office. London, 1988.

Farreld, Catherine; Morris, Jonathan. Resigned Compliance: Teacher Attitudes Towards Performance Related Pay in Schools. Educational Management Administration \& Leadership, London, v. 32, n. 1, p. 81-104, 2002.

Fuhrman, Susan H. Form the Capital to the Classroom: Standards-based Reform in the States. Chicago: The University of Chicago Press, 2001.

Glennerster, Howard. United Kingdom Education 1997-2001. Oxford Review of Economic Policy, London, v. 18, n. 2, p. 120-136, 2002.

Glennerster, Howard. Understanding the Finance of Welfare: What Welfare Costs and How to Pay for It. Bristol: The Policy Press and Social Policy Association, 2007.

Gorard, Stephen; Taylor, Chris; Fitz, John. Markets in Public Policy: the case of the United Kingdom Education Reform Act 1988. International Studies in Sociology of Education, v. 12, n. 1, p. 23-41, Dec. 2002.

Hanusher, Eric A. The failure of input-based schooling policies. The Economic Journal, v. 113, p. 64-98, Feb. 2003.

Hanusher, Eric A; Raymond, Margaret E. School Accountability ad Student Performance. Regional Economics Development, v. 2, n. 1, p.51-61, 2006.

Hood, Christopher. Peters, Guy. The Middle Aging of New Public Management: Into the Age of Paradox? Journal of Public Administration Research and Theory, v. 14, n. 3, p. $267-$ 282, July 2004.

HopkINs, David. Instructional Leadership and School Improvement. In: HARRIS, Alma; Day, Christopher; Hopkins, David. Effective Leadership for School Improvement. London: RoutledgeFalmer, 2003.

James, Chris; Vince, Russ. Developing the Leadership Capability of Headteachers. Educational Management \& Administration, v. 29, n. 3, p. 307-317, 2001.

James, Mary. Assessment for Learning: Research and Policy in the (Dis)United Kingdon. In: Berrey, Rita; Adamson, Bob. Assessment Reform in Education: Policy and Practice. London: Springer, 2010.

Johnson, Paul. Education Policy in England. Oxford Review of Economic Policy, v. 20, n. 2, p. 173-197, 2004. 
Kane, Thomas J; Staiger, Douglas O. The Promise and Pitfalls of Using Imprecise School Accountability Measures. Journal of Economic Perspective, v. 16, n. 4, p. 91-114, 2002.

Le Grand. Motivation, agency, and public policy: Of Knights \& Knaves, Pawns \& Queens. London: Oxford, 2003.

Levacic, Rosalind. Local Management of Schools. Bristol: Open University Press, 1995.

Levin, Ben. Curriculum Policy and the Politics of What Should Be Learned in Schools. In: Connelly, Michael F. The Sage Handbook of Curriculum and Instruction. California: Sage Publications, 2008.

Lynn, Laurence E. The Myth of the Bureaucratic Paradigm: What Traditional Public Administration Really Stood For? Public Administration Review, v. 61, n. 2, p. 215-234, Mar./Apr. 2001.

Maroy, Christian. The New Regulations Forms of Educational Systems in Europe: towards a Post-bureaucratic Regime. In: Soguel, Nils C; Jaccard Pierre. Governance and Performance of Education Systems. Netherlands: Springer, 2008.

Morton, Susan. Education Policy. In: Peters, Guy; Pierre, Jon. Handbook of Public Policy. London: Sage Publications, 2006.

Newton, Paul E. The Reliability of Results from National Curriculum Testing in England. Educational Research, v. 51, n.2, p. 161-179, June 2009.

OAtes, Tim. Could do better: using international comparisons to refine the National Curriculum in England. Cambridge Assessment. University of Cambridge: Nov. 2010.

Popham, James W. Standards-Based Education: Two Wrongs Don't Make a Right. In: Mathison, Sandra; ROSS, Wayne E. The Nature and Limits of Standard-Based Reform and Assessment. New York: Teachers College Press, 2008.

Rand Education. What New York City's Experiment with Schoolwide Performance Bonuses Tells Us About Pay for Performance. Disponível em: www.rand.org. Acesso em: 10 de julho de 2011.

SAint-Martin, Denis. The New Managerialism and the Policy Influence of Consultants in Government: An Historical-Institucionalist Analisys of Britain, Canada and France. International Journal of Policy and Administration, v. 11, n. 3, p. 319-356, July 1998.

Schmidt, William; PRAWAT, Richard S. Curriculum coherence and national control of education: issue or non-issue. Curriculum Studies, v. 38, n. 6, p. 641-658, 2006. SoGuEL, Nils C; JacCARD Pierre. Governance and Performance of Education Systems. Netherlands: Springer, 2008. Stoвart, Gordon. Determining Validity in National Curriculum Assessments. Educational Research, v. 51, n.2, p. 161-179, June 2009.

SvarA, James H. The Myth of the Dichotomy: Complementarity of Politics and Administration in the Past and Future of Public Administration. Public Administration Review, v. 61, n. 2, p. 215-234, Mar./Apr. 2001.

WhetTon, Chris. A brief history of a testing time: national curriculum assessment in England 1989 - 2008. Educational Research, London, v. 51, n. 2, p. 137-159, June 2009.

Whiтtr, Geoff. Twenty Years of Progress? English Education policy 1988 to the Present. Educational Management Administration \& Leadership, v. 36, n. 2, p. 165-184, Jan. 2008. 


\section{Resumo - Resumen - Abstract}

\section{O Modelo Gerencial da Educação: contribuições da experiência da Inglaterra ao} debate brasileiro

Mauricio Almeida Prado

A gestão do ensino básico na Inglaterra enfrentava fortes críticas desde a década de 1970. Havia uma série de dúvidas sobre a capacidade de o modelo inglês proporcionar educação pública de qualidade, capaz de sustentar a competitividade econômica do país. O modelo educacional neste período era pouco suscetível à prestação de contas no que se refere à qualidade, era majoritariamente analisado em termos dos montantes de recursos destinados à educação e excessivamente pautado pela autonomia pedagógica dos professores. Desde 1988, com a publicação do Education Reform Act (ERA), o sistema de educação básica na Inglaterra passou por uma reengenharia. $\mathrm{O}$ artigo tem por objetivo analisar as principais inovações implementadas e seus desdobramentos ao longo dos governos conservadores de Margareth Thatcher (1979 - 1990) e John Major (1990 - 1997), e dos governos trabalhistas de Tony Blair (1997 - 2007) e Gordon Brown $(2007$ - 2010). A relevância do tema está na discussão de uma das reformas educacionais mais influentes no mundo e na produção de insights sobre a temática de administração da educação no Brasil.

Palavras-chave: Nova Gestão Pública, reforma gerencial da educação, Inglaterra

El Modelo Gerencial de la Educación: contribuciones de las experiencias de Inglaterra para el debate brasileño

Mauricio Almeida Prado

La gestión de la educación basica en Inglaterra se enfrentó fuertes críticas desde la década de 1970. Habia una serie de dudas sobre la capacidad del modelo inglés proporcinar una educación de calidad capaz de sostener la competitividad económica del país. El modelo educacional inglés en este período era poco susceptible a una rendición de cuentas en relación a la calidad, era solamente analisado en términos de la soma de recursos destinados a la educación y excesivamente guiado por la autonomía pedagógica de los docentes. Desde 1988, con la publicación del Education Reform Act (ERA), el sistema de educación básica en Inglaterra ha sufrido un rediseño. El artículo tiene como objetivo analizar las principales innovaciones implementadas y su evolución durante los gobiernos conservadores de Margareth Thatcher (1979 - 1990) y John Major (1990 1997), y los gobiernos trabajistas de Tony Blair (1997 - 2007) y Gordon Brown (2007 - 2010). El tema tiene relevancia para la discusión de una de las reformas educativas más influyentes en el mundo y para producir conocimientos sobre el tema de la gestión de la educación en Brasil.

Palabras clave: Nueva Gestión Pública, reforma gerencial en la educación, Inglaterra

\section{The Managerial Model of Education: contributions from the Experiences of England to Brazilian Debate}

Mauricio Almeida Prado

The management of basic education in England has faced strong criticism since the 1970s. There was a lot of questions about the ability of the English model to provide a quality public education capable of sustaining the country's economic competitiveness. The English educational model in this period was slightly susceptible to accountability in terms of quality, mostly analyzed in terms of the amount of resources devoted to education and excessively guided by pedagogical autonomy of teachers. Since 1988, with the publication of the Education Reform Act (ERA), 
the basic education system in England has undergone a redesign. The article aims to analyze key innovations implemented and its developments over the Conservative governments of Margaret Thatcher (1979 - 1990) and John Major (1990 - 1997) and Labour governments of Tony Blair (1997 - 2007) and Gordon Brown (2007 - 2010). The theme has relevance to a discussion of one of the most influential educational reforms in the world and to produce insights on the theme of education management in Brazil.

Keywords: New Public Management, managerial reform of education, England

\section{Mauricio Almeida Prado}

Doutorando em Administração Pública e Governo pela Fundação Getúlio Vargas (FGV/SP) e mestre em Administração Pública pela Escola Brasileira de Administração Pública e Empresas (Ebape) da FGV/RJ. É Especialista em Políticas Públicas e Gestão Governamental, em exercício na Secretaria de Educação Básica do Ministério da Educação. Contato:maupra@uol.com.br 